\title{
Front Matter: Volume 8416
}

, "Front Matter: Volume 8416," Proc. SPIE 8416, 6th International Symposium on Advanced Optical Manufacturing and Testing Technologies: Advanced Optical Manufacturing Technologies, 841601 (16 October 2012); doi: $10.1117 / 12.2012104$

Event: 6th International Symposium on Advanced Optical Manufacturing and Testing Technologies (AOMATT 2012), 2012, Xiamen, China 


\title{
6th International Symposium on Advanced Optical Manufacturing and Testing Technologies
}

\section{Advanced Optical Manufacturing Technologies}

\author{
Li Yang \\ Eric Ruch \\ Shengyi Li \\ Editors
}

\section{6-29 April 2012 \\ Xiamen, China}

Sponsored by

COS-The Chinese Optical Society (China)

IOE-The Institute of Optics and Electronics, CAS (China)

Technical Cosponsor

SPIE

Supporting Organizations

Ministry of Science and Technology of China (China)

Chinese Academy of Sciences (China)

National Natural Science Foundation of China (China)

Published by

SPIE 
The papers included in this volume were part of the technical conference cited on the cover and title page. Papers were selected and subject to review by the editors and conference program committee. Some conference presentations may not be available for publication. The papers published in these proceedings reflect the work and thoughts of the authors and are published herein as submitted. The publisher is not responsible for the validity of the information or for any outcomes resulting from reliance thereon.

Please use the following format to cite material from this book:

Author(s), "Title of Paper," in 6th International Symposium on Advanced Optical Manufacturing and Testing Technologies: Advanced Optical Manufacturing Technologies, edited by Li Yang,

Eric Ruch, Shengyi Li, Proceedings of SPIE Vol.8416 (SPIE, Bellingham, WA, 2012) Article CID Number.

ISSN: 0277-786X

ISBN: 9780819490988

Published by

SPIE

P.O. Box 10, Bellingham, Washington 98227-0010 USA

Telephone +1 3606763290 (Pacific Time) · Fax +1 3606471445

SPIE.org

Copyright (C) 2012, Society of Photo-Optical Instrumentation Engineers.

Copying of material in this book for internal or personal use, or for the internal or personal use of specific clients, beyond the fair use provisions granted by the U.S. Copyright Law is authorized by SPIE subject to payment of copying fees. The Transactional Reporting Service base fee for this volume is $\$ 18.00$ per article (or portion thereof), which should be paid directly to the Copyright Clearance Center (CCC), 222 Rosewood Drive, Danvers, MA 01923. Payment may also be made electronically through CCC Online at copyright.com. Other copying for republication, resale, advertising or promotion, or any form of systematic or multiple reproduction of any material in this book is prohibited except with permission in writing from the publisher. The CCC fee code is 0277-786X/12/\$18.00.

Printed in the United States of America.

Publication of record for individual papers is online in the SPIE Digital Library.

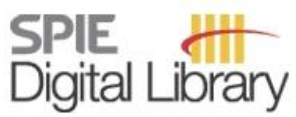

SPIEDigitalLibrary.org

Paper Numbering: Proceedings of SPIE follow an e-First publication model, with papers published first online and then in print and on CD-ROM. Papers are published as they are submitted and meet publication criteria. A unique, consistent, permanent citation identifier (CID) number is assigned to each article at the time of the first publication. Utilization of CIDs allows articles to be fully citable as soon as they are published online, and connects the same identifier to all online, print, and electronic versions of the publication. SPIE uses a six-digit CID article numbering system in which:

- The first four digits correspond to the SPIE volume number.

- The last two digits indicate publication order within the volume using a Base 36 numbering

system employing both numerals and letters. These two-number sets start with $00,01,02,03,04$, 05, 06, 07, 08, 09, 0A, OB ... 0Z, followed by 10-1Z, 20-2Z, etc.

The CID Number appears on each page of the manuscript. The complete citation is used on the first page, and an abbreviated version on subsequent pages. Numbers in the index correspond to the last two digits of the six-digit CID Number. 


\title{
Contents
}

\author{
xiii Symposium Committee \\ $\mathrm{xV}$ Introduction \\ xvii AOMATT 2012 Sponsors
}

INVITED SESSION

841602 Research on fabrication of mirror segments for E-ELT (Invited Paper) [8416-205]

G. Yu, OpTIC Glyndwr Ltd. (United Kingdom); D. D. Walker, OpTIC Glyndwr Ltd. (United Kingdom), Univ. College London (United Kingdom), and Zeeko Ltd. (United Kingdom); H. Li, Univ. College London (United Kingdom)

841603 Development of a flexible and reliable numerical simulation for precision glass molding of complex glass optics (Invited Paper) [8416-35]

F. Klocke, F. Wang, Y. Wang, G. Liu, O. Dambon, Fraunhofer Institute for Production

Technology (Germany); A. Y. Yi, The Ohio State Univ. (United States)

841604 Asphere metrology using variable optical null technology (Invited Paper) [8416-204]

C. Supranowitz, C. McFee, P. Murphy, QED Technologies, Inc. (United States)

\section{SESSION 2-1}

841605 Numerical simulation of temperature field and experimental inquiry of TC4 titanium alloy laser rapid forming [8416-1]

Y. Lai, Shenyang Institute of Automation (China) and Graduate Univ. of Chinese Academy of Sciences (China); W. Liu, Shenyang Institute of Automation (China); Y. Kong, F. Wang, Shenyang Institute of Automation (China) and Graduate Univ. of Chinese Academy of Sciences (China); Y. Zhao, Shenyang Institute of Automation (China)

841606 Precision manufacturing of fused silica glass by combining bound-abrasive polishing with ultrasonic vibration [8416-53]

Y. Li, Akita Prefectural Univ. (Japan) and Chengdu Fine Optical Engineering Research Ctr. (China); Y. Wu, Akita Prefectural Univ. (Japan); J. Wang, Q. Xu, Chengdu Fine Optical Engineering Research Ctr. (China); W. Yang, Y. Guo, Xiamen Univ. (China)

841607 A large ion beam figuring plant used for manufacturing astronomical telescope [8416-61] W. Guo, B. Liang, X. Cheng, Y. Zheng, Nanjing Institute of Astronomical Optics \& Technology (China)

841608 Progresses in optical design and simulation optimization methods [8416-73]

H. Liu, Q. Ding, National Key Lab. of Science and Technology on Fire Control (China);

L. Zhou, Beijing Institute of Technology (China) 
841609 Supersmooth polishing with sub-angstron roughness [8416-75]

J. Wang, Changchun Institute of Optics, Fine Mechanics and Physics (China)

$84160 \mathrm{~A}$ Lapping application research for touch screen glass using $3 \mathrm{M}$ fine grade Trizact diamond tile [8416-94]

L. Zheng, 3M South China Technical Ctr. (China); T. K. Na, 3M R\&D Ctr. (Singapore)

8416 OB Novel method for fabricating steep aspheric mirrors [8416-107]

Y. Shu, S. Li, X. Zuo, C. Song, Y. Wang, National Univ. of Defense Technology (China)

SESSION 2-2

$84160 \mathrm{C}$ An integrated approach for design, ultraprecision polishing, and measurement of freeform progressive lenses [8416-102]

C. F. Cheung, L. B. Kong, L. T. Ho, S. To, B. Wang, K. T. Lai, The Hong Kong Polytechnic Univ. (Hong Kong, China)

8416 OD Development of an externally pressurized bearing-rotor system for a five-axis ultraprecision machine tool used for optical manufacture and the static performance analysis of the externally pressurized bearing [8416-47]

E. Qi, Z. Fang, T. Sun, J. Zhou, G. Hou, Harbin Institute of Technology (China)

8416 OE Study on combination technology in off-axis asphere manufacture [8416-500]

Y. Wang, S. Li, X. Peng, X. Nie, C. Song, National Univ. of Defense Technology (China)

8416 OF Insights into effects of thermal annealing on optical properties of $\mathrm{SiO}_{2}$ films [8416-51]

Y. Jiang, Tongji Univ. (China) and Tianjin Jinhang Institute of Technical Physics (China); Y. Ji, Tianjin Jinhang Institute of Technical Physics (China) and Harbin Institute of Technology (China); H. Liu, D. Liu, L. Wang, C. Jiang, Tianjin Jinhang Institute of Technical Physics (China); Y. Yang, Tongji Univ. (China); D. Chen, Harbin Institute of Technology (China)

$84160 \mathrm{G}$ Study on UVC ultraviolet filter film [8416-19]

Y. Kou, X. Fu, D. Liu, H. Zhu, H. Tang, Changchun Univ. of Science and Technology (China)

\section{SESSION 2-3}

$8416 \mathrm{OH}$ Study on the synthesis and optical properties of polyurethane-imide [8416-203]

L. D. Wang, Southeast Univ. (China) and Huainan Normal Univ. (China); T. Zhang,

X.-Y. Zhang, R.-Z. Li, L.-N. Wang, S.-Q. Zhu, Southeast Univ. (China)

8416 ol Illuminator design for small field ArF lithography system [8416-145]

L. Wei, Y. Li, K. Liu, X. Liu, Beijing Institute of Technology (China)

$84160 \mathrm{~J}$ Data filtering of optical freeform measurement based on a modified 2D cascaded approximating spline filter [8416-109]

Q. Wang, X. Zhang, Y. Peng, F. Fang, Tianjin Univ. (China) 
8416 OK Evolution and control of optical thin film stress [8416-206]

M. Fang, Shanghai Institute of Optics and Fine Mechanics (China); J. Li, Shanghai Institute of Optics and Fine Mechanics (China) and Graduate Univ. of Chinese Academy of Sciences (China); H. He, Z. Fan, Q. Xiao, Z. Y. Li, Shanghai Institute of Optics and Fine Mechanics (China)

POSTER SESSION

$8416 \mathrm{OL}$ An on-line condition monitoring and monitoring point position visual system in grinding [8416-11]

W. Han, W. Yang, Y. Guo, T. Jiang, C. J. Wang, Xiamen Univ. (China)

$84160 \mathrm{M}$ High performance narrow band-pass filter for the NIR/MWIR range [8416-69]

X. Su, W. Wu, K. Yan, F. Chen, C. Meng, LuoYang Optoelectro Technology Development Ctr. (China)

8416 ON Tri-rotors movement in computer controlled optical surfacing [8416-83]

X. Chen, P. Guo, J. Ren, Soochow Univ. (China)

841600 The research on making large-size aspherical mirrors by vacuum evaporation technique [8416-207]

J. Wang, Nanjing Institute of Astronomical Optics \& Technology (China)

8416 OP Polishing large-aperture mirror using ultraprecise Bonnet and PSD result analysis [8416-98] W. Wang, M. Xu, Fudan Univ. (China); H. Li, Harbin Institute of Technology (China), Univ. College London (United Kingdom), and OpTIC Glyndwr Ltd. (United Kingdom); G. YU, OpTIC Glyndwr Ltd. (United Kingdom)

$84160 Q \quad$ Optimum parameters for precision compression molding of spherical glass-lens arrays [8416-7]

J. Lu, J. Wang, M. Xu, H. Zhang, Fudan Univ. (China)

8416 OR Manufacturing technology of lightweight mirror for space optics [8416-9]

Y. Chen, J. Xie, Changchun Institute of Optics, Fine Mechanics and Physics (China)

8416 OS Design and manufacture of anti-IR thin films for resin lens [8416-15]

J. Chen, H. Feng, H. Chen, C. Hu, Y. Li, Wenzhou Medical College (China)

8416 OT An adaptive interpolation method for tool path generation based on iso-phote for large scale wedge /aspheric lens element grinding [8416-5]

N. Zhang, Xiamen Univ. (China) and Zhejiang Univ. of Technology (China); F. Yang,

D. Zhang, M. Chen, Z. Wang, Y. Guo, Xiamen Univ. (China)

$84160 \mathrm{U}$ Goniometer system of vehicle anti-tank missile design [8416-208]

M. Yan, X. Shan, H. Zhao, Changchun Institute of Technology (China) 
8416 OV Influence of substrate rotating on the microstructure and surface morphology of Ge and Si thin films [8416-21]

H. Luo, Shanghai Institute of Technical Physics (China) and Graduate Univ. of Chinese Academy of Sciences (China); D. Liu, Shanghai Institute of Technical Physics (China); X. Yin, Shanghai Institute of Technical Physics (China) and Graduate Univ. of Chinese Academy of Sciences (China)

$84160 \mathrm{~W}$ Study on the applications of high-precision optical wedge machining, assembling, and adjustment technologies [8416-30]

Y. SU, R. Guo, J. Shi, Y. Zhang, F. Zhang, X. Liu, H. Zhao, Xi'an Institute of Applied Optics (China)

$84160 X \quad H i g h$ efficient and ultra-precision machining of large scale SiC plane reflectors [8416-24]

R. Guo, Y. Su, C. Chen, Y. Zhang, F. Zhang, X. Liu, Xi'an Institute of Applied Optics (China)

8416 OY Effects analysis of large area polishing tool on aspheric surface quality [8416-33]

Y. Zhang, F. Zhang, J. Yan, Y. Su, R. Guo, X. Liu, Xi'an Institute of Applied Optics (China)

$84160 Z$ Fabrication and measurement of toric lens [8416-34]

X. Liu, Y. Su, H. He, Y. Zhang, R. Guo, F. Zhang, Xi'an Institute of Applied Optics (China)

841610 Aspheric surface profile effects analysis in polishing with ballonet polishing tool [8416-25] F. Zhang, Y. Zhang, Xi'an Institute of Applied Optics (China); W. Kang, Xi'an North Optoeletronic Science and Technology Defense Co. Ltd. (China); Y. Su, C. Chen, X. Liu, Xi'an Institute of Applied Optics (China)

841611 Design and fabrication of high efficiency diffuser film based on laser speckle [8416-23] Y. Li, X. Ren, S. Liu, Xiamen Univ. (China)

841612 Bonnet polishing high-slope aspheric surface [8416-108]

J. Zhang, Changchun Institute of Optics, Fine Mechanics and Physics (China)

841613 Study on range selection of key parameters in bonnet polishing using FEA [8416-10] R. Pan, Z. Wang, D. Zhang, C. Wang, Y. Xie, Y. Guo, Xiamen Univ. (China)

841614 Research on a two ball lens system POF connector [8416-54]

Z. Huang, G. Liu, Z. Ren, L. Zeng, Q. Wan, Jiangxi Science and Technology Normal Univ. (China)

841615 Simulation of high-resolution linear CCD satellite image [8416-92]

R. Zhang, S. Luo, G.-W. Jiang, T. Jiang, Information Engineering Univ. (China); M. Sun, People's Liberation Army (China)

841616 Study on object-oriented petri net in modeling for infrared dome optical manufacturing [8416-45]

H. Wang, Northwestern Polytechnical Univ. (China) and LuoYang Optoelectro Technology Development Ctr. (China); H. Chen, LuoYang Optoelectro Technology Development Ctr. (China)

841617 Custom design of aspherical RGP contact lens [8416-16]

C. Hu, Y. Li, J. Chen, Y. Wang, S. Chen, H. Chen, Wenzhou Medical College (China) 
841618 Study on the optical manufacture and testing methods of a refractive-reflective meniscus primary mirror [8416-93]

J. Kang, Changchun Institute of Optics, Fine Mechanics and Physics (China) and Graduate Univ. of Chinese Academy of Sciences (China); B. Xuan, Changchun Institute of Optics, Fine Mechanics and Physics (China); J. Xie, Graduate Univ. of Chinese Academy of Sciences (China)

841619 Key technologies for diamond turning of non-rotational symmetrical micro-structured surfaces [8416-43] J. Zhou, T. Sun, G. Hou, E. Qi, Harbin Institute of Technology (China)

8416 1A An efficient CNC polishing technology of aspherical parabolic cylindrical lens [8416-64] Q. Huang, H. Chen, S. Hu, LuoYang Optoelectro Technology Development Ctr. (China)

8416 1B Effects of structured surface errors on MTF of off-axis TMA system [8416-13] X. Zeng, Changchun Institute of Optics, Fine Mechanics and Physics (China) and Graduate Univ. of Chinese Academy of Sciences (China); F. Yan, X. Zhang, Changchun Institute of Optics, Fine Mechanics and Physics (China)

8416 1C The study on errors of prisms of a quarter-width camera system [8416-138] P. Xie, L. Xing, Changchun Institute of Optics, Fine Mechanics and Physics (China)

8416 1D Study on the control of surface roughness in single point diamond turning [8416-56] H. Xu, X. Zhang, Fudan Univ. (China); M. Xu, Fudan Univ. (China) and Modern Advanced Ultra-Precision Manufacturing Ctr. (China); X. Li, Modern Advanced Ultra-Precision Manufacturing Ctr. (China)

8416 IE Magnetic medium assistant polishing technology and experiments [8416-135] W. Deng, L. Zheng, F. Zhang, Changchun Institute of Optics, Fine Mechanics and Physics (China)

8416 1F Aging effect of optical properties on $\mathrm{SiO}_{2}$ films grown on Si substrates by ion beam sputtering [8416-77]

Y. Ji, Harbin Institute of Technology (China) and Tianjin Jinhang Institute of Technical Physics (China); H. Liu, Tianjin Jinhang Institute of Technical Physics (China); Y. Jiang, Tianjin Jinhang Institute of Technical Physics (China) and Tongji Univ. (China); D. Liu, L. Wang, C. Jiang, Tianjin Jinhang Institute of Technical Physics (China); R. Fan, D. Chen, Harbin Institute of Technology (China)

$84161 G$ Design and manufacture of high reflective coatings deposited on metal substrate [8416-101]

L. Wang, H. Liu, Y. Jiang, C. Jiang, Y. Ji, Tianjin Jinhang Institute of Technical Physics (China)

$84161 \mathrm{H}$ Multi-channel optical telescope with free-form surface splitters [8416-89]

X. Li, M. XU, Fudan Univ. (China); X. Ren, Jining Medical Univ. (China)

841611 Optimization of freeform cylindrical lens in Czerny-Turner spectrometer system to correct the astigmatism by using user defined error function [8416-22]

B. Qu, G. Xia, F. Yu, Zhejiang Univ. (China) 
$84161 \mathrm{~J}$ Analysis and optimization of tooth shapes of roll stampers for optical micro-structured array imprinting [8416-131]

S. Yang, X. Zhang, M. Xu, Fudan Univ. (China)

$84161 \mathrm{~K} \quad$ Eight-axis-polishing machine for $\mathbf{2} \mathbf{m}$ off-axis aspheric optics [8416-209]

H.-G. Rhee, H.-S. Yang, I.-K. Moon, H. Kihm, J.-H. Lee, Y. Ghim, Y.-W. Lee, Korea Research Institute of Standards and Science (Korea, Republic of)

$84161 \mathrm{~L}$ Investigation on the MTF for the large-aperture long focal length TDICCD camera [8416-57] J. Xin, Beijing Institute of Space Mechanics and Electricity (China)

$84161 \mathrm{M} \quad$ Correction of full spatial frequency errors with ion beam figuring [8416-104]

Y. Gu, Changchun Institute of Optics, Fine Mechanics and Physics (China) and Graduate Univ. of Chinese Academy of Sciences (China)

$84161 \mathrm{~N}$ Analysis of chemical polishing for optical elements [8416-88]

L. Jiao, Y. Jin, N. Lin, T. Liu, Y. Tong, D. Wu, C. Hui, Tianjin Jinhang Institute of Technical Physics (China)

$841610 \quad$ Ultra-precision surface polishing using ion beam figuring [8416-31]

Y.-S. Ghim, S.-J. You, H.-G. Rhee, H.-S. Yang, Y.-W. Lee, Korea Research Institute of Standards and Science (Korea, Republic of)

$84161 \mathrm{P} \quad$ Design of primary mirror supporting structure and lightweight of space camera [8416-154] C. Zhu, T. Xu, Tongji Univ. (China); S. Liu, B. Yang, Y. Liu, Shanghai Institute of Technical Physics (China)

$84161 Q \quad$ Anti-reflection coating on calcium fluoride substrate using ion-assisted deposition [8416-80] Y. Zhang, J. Fan, H. Xu, Institute of Optics and Electronics (China)

$84161 R \quad$ Research on spectral calibration for hyper-spectral imager [8416-200]

Y. Guo, Y. Li, X. Zong, Beijing Institute of Space Mechanics and Electricity (China)

8416 1S Rigidity controllable polishing tool based on magnetorheological effect [8416-41] J. Wang, Institute of Optics and Electronics (China) and Graduate Univ. of Chinese Academy of Sciences (China); Y. Wan, C. Shi, Institute of Optics and Electronics (China)

$84161 \mathrm{~T}$ Application of two-sided prisms in pyramid wavefront sensor [8416-71] J. Wang, Southwest Univ. of Science and Technology (China) and Institute of Optics and Electronics (China); C. Guan, Institute of Optics and Electronics (China)

$84161 \mathrm{U} \quad$ Laser beam shaping and packaging system [8416-85]

D. Luo, B. Zhao, Institute of Semiconductors (China)

$84161 \mathrm{~V}$ The exploration of cloud manufacturing service mode for high power laser optical elements [8416-132]

J. Wang, J. Wang, Y. Tao, H. Li, W. Li, L. Jiang, Institute of Computer Application (China)

$84161 \mathrm{~W}$ Effect of hydrodynamic pressure on ultraprecision grinding [8416-210]

Y. Hwang, H.-J. Kim, J.-H. Kim, Korea Photonics Technology Institute (Korea, Republic of) 
$84161 \mathrm{X}$ Machining simulation of off-axis parabolic hexagonal mirrors [8416-36]

$X$. Feng, Institute of Optics and Electronics (China) and Graduate Univ. of Chinese Academy of Sciences (China); B. Fan, Institute of Optics and Electronics (China)

$84161 Y$ Study on the best arrangement of sensors used in the deformation measurement of active lap based on genetic algorithm [8416-38]

$\mathrm{H}$. Zhao, Institute of Optics and Electronics (China) and Graduate Univ. of Chinese Academy of Sciences (China); X. Li, Z. Zeng, Institute of Optics and Electronics (China)

841612 Introduction and manufacturing of oblate spheroid mirror [8416-211]

D. Li, L. Yuan, L. He, B. Wang, Nanjing Institute of Astronomical Optics \& Technology (China)

841620 Ultraprecision optical fabrication on fused silica [8416-76]

J. Wang, Changchun Institute of Optics, Fine Mechanics and Physics (China)

841621 Generation of radially polarized femtosecond pulse beam with a polarization plates array [8416-130]

J. Qi, National Univ. of Defense Technology (China) and Military Academy of PLA (China); Y. Nie, X. Wang, J. Liao, J. Liu, J. Yang, H. Jia, X. Li, National Univ. of Defense Technology (China)

841622 Mathematical model for active lap to achieve unsymmetrical fabrication [8416-65] H. Liu, Institute of Optics and Electronics (China) and Graduate Univ. of Chinese Academy of Sciences (China); Z. Zeng, F. Wu, B. Fan, Institute of Optics and Electronics (China)

841623 A study of new optimization of LED projector with high efficiency and contrast [8416-212] Y.-C. Fang, C.-A. Chen, National Kaohsiung First Univ. of Science and Technology (Taiwan); C.-M. Tsai, Kun Shan Univ. (Taiwan); C.-T. Yen, National Formosa Univ. (Taiwan); H.-Y. Wu, C.-H. Chu, National Kaohsiung First Univ. of Science and Technology (Taiwan)

841624 Preform rod feeding module of the optical fiber drawing tower and its algorithm design based on STM32 [8416-156]

T. Zhang, Z. Fan, G. Liu, T. Geng, X. Li, Harbin Engineering Univ. (China)

841625 Reconstructing in laser wavelength scanning interference test of aspheric surface [8416-202]

L. Li, Institute of Optics and Electronics (China) and Sichuan Univ. (China); W. Zhao, Institute of Optics and Electronics (China); X. Su, Sichuan Univ. (China); F. Wu, B. Fan, Institute of Optics and Electronics (China)

841626 Experimental study of grinding removal efficiency in optical processing for using NC manipulator [8416-91]

W. Zhang, Institute of Optics and Electronics (China) and Graduate Univ. of Chinese Academy of Sciences (China); Z. Zeng, F. WU, B. Zhuo, Institute of Optics and Electronics (China)

841627 A new method of calibrating the spatial coordinate coherence of shadowgraph-taking camera stations at the long distance with PSD [8416-58]

J. Li, X. Wang, H. Shen, R. Zhu, Y. Huang, S. Rong, Y. Bian, Nanjing Univ. of Science and Technology (China) 
841628 Ultraprecision turning experiments of micro-holes on GDP capsule [8416-29]

G. Li, Y. Huang, W. Tong, K. Du, Research Ctr. of Laser Fusion (China)

841629 Elimination of the imprinting effect of the lightweight aspheric polished by CCAL technology using immersed inflation [8416-79]

X. Zhong, Q. XU, B. Fan, J. Zhou, Institute of Optics and Electronics (China)

8416 2A Two-dimensional of uniform irradiation on target with the use of the concentricity deviation lens arrays focus system of variable focus length [8416-72]

J. Zheng, Dalian Nationalities Univ. (China) and Dalian Univ. of Technology (China); Q. YU, Dalian Univ. of Technology (China); Y. Lu, Dalian Nationalities Univ. (China); S. Guan, Dalian Nationalities Univ. (China) and Dalian Univ. of Technology (China); B. Dong, Dalian Nationalities Univ. (China)

$84162 \mathrm{~B}$ Effects of colloid rheological characters in ultra-smooth polishing by nanoparticle colloid jet machining [8416-90]

X. Song, Lanzhou Univ. Of Technology (China); Y. Zhang, F. Zhang, Harbin Institute of Technology (China)

$84162 \mathrm{C}$ Comparative analysis of three-position measurement technology and multi-positions average measurement technology [8416-84]

P. Yang, Guiyang Univ. (China) and Institute of Optics and Electronics (China); F. Wu, $X$. Hou, Institute of Optics and Electronics (China)

8416 2D Research on $\mathrm{SiO}_{2}$ film laser damage threshold [8416-42]

T. Wang, L. Yang, Xi'an Technological Univ. (China)

$84162 \mathrm{E}$ Thermal-structural-optical analysis for the lens of high-precision interferometer [8416-40] J. Zhang, Y. Wu, F. Wu, Institute of Optics and Electronics (China)

$84162 \mathrm{~F}$ Optical aligning and measuring methods for large aperture optical system [8416-110] X. Zhang, R. Wei, J. Duan, J. Yang, H. Li, X. Hou, Xi'an Institute of Optics and Precision Mechanics (China)

$84162 \mathrm{G} \quad$ Noise factor of microchannel plate with ion barrier film [8416-99]

S. Liu, Science and Technology on Low-Light-Level Night Vision Lab. (China) and Institute of High Energy Physics (China); F. Shi, Z. Li, Y. Zhu, N. Zhang, Science and Technology on LowLight-Level Night Vision Lab. (China); Y. Gu, J. Sun, X. Cong, H. Zhao, J. Pan, Y. Qian,

S. Zheng, B. Chang, Nanjing Univ. of Science and Technology (China)

$84162 \mathrm{H} \quad$ Kinematical analysis of one-axis polisher acting on spherical mirror [8416-63]

L. Xu, J. Ding, Z. Ma, Q. Chen, Xi'an Institute of Optics and Precision Mechanics (China)

$841621 \quad$ Manufacturing of glass-based optical power splitter by ion-exchange method [8416-46] Y. Xiao, J. Yang, M. Wang, Zhejiang Univ. (China)

$84162 \mathrm{~J}$ Design and experiments of a novel micro-displacement mechanism based on piezoelectricity actuator [8416-32]

Y. Li, Harbin Institute of Technology (China) and Heilongjiang Univ. of Chinese Medicine (China); J. Wang, W. Zhai, S. Dong, G. Li, Harbin Institute of Technology (China) 
$84162 \mathrm{~K}$ Self-generated magnetic fields in the relativistic laser-plasma interaction [8416-95] A. Abudurexiti, Xinjiang Univ. (China)

$84162 \mathrm{~L} \quad$ Preferential sputtering of Ar ion processing $\mathrm{SiO}_{2}$ mirror [8416-28]

G. Duan, Institute of Optics and Electronics (China) and Graduate Univ. of Chinese Academy of Sciences (China); T. Xing, Y. Li, Institute of Optics and Electronics (China)

$84162 \mathrm{M}$ Optimization of the edge extension in dwell time algorithm for ion beam figuring [8416-37] L. Shu, Institute of Optics and Electronics (China) and Graduate Univ. of Chinese Academy of Sciences (China); F. Wu, C. Shi, Institute of Optics and Electronics (China)

$84162 \mathrm{~N}$ Hybrid refractive/diffractive optical system design for light and compact uncooled longwave infrared imager [8416-68]

$\mathrm{H}$. Wang, Northwestern Polytechnical Univ. (China) and Xi'an Institute of Optics and Precision Mechanics (China); Y. Bai, Institute of Optics and Electronics (China); J. Luo, Northwestern Polytechnical Univ. (China)

841620 A new numerical calculation method for the characteristics of hydrostatic slide [8416-20] G. Hou, T. Sun, J. Zhou, E. Qi, Harbin Institute of Technology (China)

$84162 \mathrm{P} \quad$ Research on theoretical analysis of active fluid jet polishing [8416-213]

T. Sun, L. Sun, F. Wang, S. Liu, Dalian Institute of Chemical and Physics (China)

$84162 Q \quad$ Fabrication of supersmooth optical elements with low surface and subsurface damage [8416-159]

G. Zhan, Z. Shen, B. Ma, X. Wang, Z. Wang, Tongji Univ. (China); H. Liu, Y. Ji, Tongji Univ. (China) and Tianjin Jinhang Institute of Technical Physics (China)

Author Index 
Proc. of SPIE Vol. $8416841601-12$

Downloaded From: https://www.spiedigitallibrary.org/conference-proceedings-of-spie on 26 Apr 2023 Terms of Use: https://www.spiedigitallibrary.org/terms-of-use 


\title{
Symposium Committee
}

\author{
Honorary Chair
}

Bingkun Zhou, Chinese Optical Society (China)

Symposium General Chair

Liwei Zhou, Beijing Optical Society (China)

Symposium General Cochairs

Jianlin Cao, Ministry of Science and Technology of China

Hiroki Kuwano, Nano Center of Tohoku University (Japan)

Yudong Zhang, Institute of Optics and Electronics (China)

Fritz Klocke, Fraunhofer Institute for Production Technology (Germany)

Wenhan Jiang, Institute of Optics and Electronics (China)

Jianzhong Xu, Chinese Academy of Sciences Institute of Engineering Thermophysics (China)

Ying Zhang, Xiamen University (China)

Xipeng Xu, Huaqiao University (China)

International Academic Committee

Wenhan Jiang, Chair, Chinese Academy of Engineering (China)

Liwei Zhou, Chinese Academy of Engineering (China) and Beijing Institute of Technology (China)

Jianzhong Xu, Institute of Engineering Thermophysics (China)

Xiangdi Lin, Chinese Academy of Engineering (China)

Pan Junhua, Chinese Academy of Engineering (China) and Soochow University (China)

Hiroki Kuwano, Tohoku University (Japan)

Fritz Klocke, Fraunhofer Institute for Production Technology (Germany)

James R. Torley, University of Colorado (United States)

Yoshiharu Namba, Chubu University (Japan)

James H. Burge, University of Arizona (United States)

Myung K. Cho, National Optical Astronomy Observatory

(United States)

Jose M. Sasian, University of Arizona (United States) 
Organizing Committee

Yudong Zhang, Cochair, IOE, CAS

Jinghua Cao, Cochair, Deputy Secretary for International Cooperation, CAS (China)

Libin Xiang, Cochair, Academy of Optoelectronics (China)

Anand Asundi, Cochair, Singapore Institute of Optics and Photonics (China)

Guoqiang Ni, Cochair, Chinese Optical Society (China)

Chenxu Wu, Cochair, Xiamen University (China)

Yadong Jiang, Cochair, University of Electronic Science and Technology (China)

Jiaxian Wang, Cochair, Huaqiao University (China)

Zhifeng Wang, Cochair, Institute of Electrical Engineering (China)

Lin Wang, Cochair, Optics and Optoelectronics Industry Society of China (China)

Program Committee

Xiangdi Lin, Chair, Chinese Academy of Engineering (China)

Yang Hu, Cochair, IOE, CAS (China)

Yuwen Qing, Cochair, Natural Science Foundation of China (China)

Haodong Yu, Cochair, Changchun University of Science and Technology (China)

Yoshiharu Namba, Cochair, Chubu University (Japan)

Myung K. Cho, Cochair, National Optical Astronomy Observatory (United States)

Secretariat General of the Symposium

Li Yang, Committee of Optical Manufacturing Technology (China) Jinxue Wang, SPIE

Session Chairs

Session 1-1 Fan Wu

Session 2-1 Qiming Xin

Session 3-1 Shangming Wen

Session 4-1 Xuefeng Liu

Session 5-1 Lei Zhang

Session 6-1 Rongzhu Zhang

Session 8-1 Tingwen Xing

Session 1-2 Bin Fan

Session 2-2 Rongzhu Zhang
Session 3-2 Sandy To

Session 4-2 Yanqiu Li

Session 5-2 Hui Lin

Session 7-1 Shangming Wen

Session 8-2 Tingwen Xing

Session 2-3 Qiming Xin

Session 3-3 Shangming Wen

Session 5-3 Zhu Ma 


\section{Introduction}

The 6th International Symposium on Advanced Optical Manufacturing and Testing Technology (AOMATT) was held 26-29 April 2012 at the Xiamen International Conference Center, Xiamen, China.

AOMATT 2012 was kicked off on April 26 with a formal opening ceremony. The ceremony started with the introduction of VIP guests, symposium chairs, and conference chairs, followed by opening speeches by Prof. Liwei Zhou, AOMATT 2012 Symposium Chairman, Prof. Bin XU, Vice President of IOE, sponsor of AOMATT2012, and Dr. H. Philip Stahl, Vice President of SPIE, technical cosponsor of AOMATT2012. Plenary sessions started immediately after the conclusion of the opening ceremony. There were a total of 10 plenary presentations: Dr. H. Philip Stahl, 2012 SPIE Vice President and NASA Marshall Space Flight Center (USA); Prof. Hiroki Kuwano, 2012 President of Japanese Mechanics Society and Director of Micro/Nano Center, Tohoku University (Japan); Dr. Fritz Klocke, President of Fraunhofer Institute for Production Technology IPT (Germany); Dr. James Burge, Professor of Optical Sciences and Astronomy at the University of Arizona (USA); Dr. Eric Ruch, SAGEM (France); Dr. Tilmann Heil, Director of System Engineering, Carl Zeiss SMT GmbH (Germany); Prof. W. B. Lee, Professor of Manufacturing Engineering and Director of Advanced Technology Manufacturing Research Centre, Hong Kong Polytechnic University; Dr Fengzhou Fang, Professor of Precision Measurement Technology and Instruments at Tianjin University (China); Prof. Shengyi Li, Professor of Mechatronics and Automation at the National University of Defense Technology (China). More than 1,000 people attended the opening ceremony and full-day plenary sessions.

More than 1,000 abstracts were submitted to AOMATT2012, and from these about 500 oral and poster papers were selected. Oral papers were presented in 8 parallel conferences on April 27 and 28. An all-symposium poster session was held in the afternoon of April 28. All of the parallel conference sessions and the poster session were well attended. Authors and attendees had active discussions and exchange of ideas throughout the symposium. Many papers presented cuttingedge research and development work in optical design, manufacturing, and testing. The success of AOMATT2012 continued the tradition of focus and excellence of this biannual international topical symposium in China.

We would like to express our sincere appreciation to COS - The Chinese Optical Society, IOE - Institute of Optics and Electronics, Chinese Academy of Sciences, and SPIE for sponsoring and supporting AOMATT2012. We want to thank all authors and participants for their contributions to the symposium and sharing their research with colleagues around the world. The 7th AOMATT is planned for 2014. 
We look forward to seeing everyone at AOMATT2014. Please watch for the Call for Papers and symposium announcements on SPIE and IOE web sites.

Li Yang

Jinxue Wang

Secretary General, AOMATT 20102 


\section{AOMATT 2012 SPONSORS}

Sponsored by

COS-The Chinese Optical Society (China)

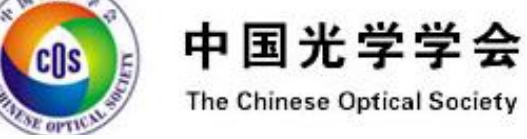

IOE-The Institute of Optics and Electronics, CAS (China)

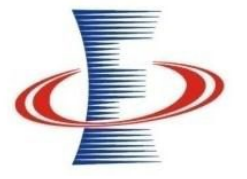

中国科学院光电技术研究所

THE INSTITUTE OF OPTICS AND ELECTRONICS

THE CHINESE ACADEMY OF SCIENCES

Technical Cosponsor

SPIE

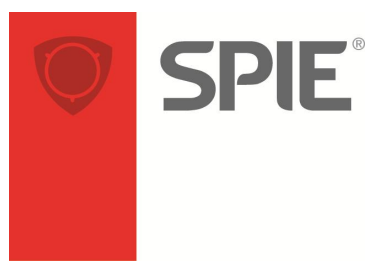

Supporting Organizations

Ministry of Science and Technology of China

Chinese Academy of Sciences

National Natural Science Foundation of China

\section{Cooperating Organizations}

Micro/Nano Science and Tech. Committee, Japan Society of Mechanical

Engineering • Application Optical Society of Germany • Optics and Photonics

Society of Singapore - Optoelectronic Industry Association of China • The Optical Society of Sichuan Province of China - State Key Laboratory of Optical

Technologies for Microfabrication, IOE, CAS - Key Laboratory on Adaptive Optics, IOE, CAS • National Univ. of Defense Tech. (China) • Univ. of Electronic Science and Tech. of China - Sichuan Univ. (China) - Xiamen University (China) • Huaqiao Univ. (China) • Hong Kong Polytechnic Univ. (Hong Kong China) • Harbin Inst. of Tech. (China) - Changchun Inst. of Optics, Fine Mechanics and Physics, CAS Changchun Univ. of Science and Tech. (China) • Beijing Inst. of Tech. (China) Univ. of Shanghai for Science \& Tech. (China) - Nanjing Univ. of Science and Tech. (China) • Inst. of Electrical Engineering, CAS 
Proc. of SPIE Vol. $8416841601-18$

Downloaded From: https://www.spiedigitallibrary.org/conference-proceedings-of-spie on 26 Apr 2023 Terms of Use: https://www.spiedigitallibrary.org/terms-of-use 